\title{
MASSIVE OPEN ONLINE COURSES - A MODERN FORM OF DISTANCE EDUCATION
}

\author{
G. Kiryakova* \\ Faculty of Economics, Trakia University, Stara Zagora, Bulgaria
}

\begin{abstract}
Distance education has proven its advantages over time as a form of learning that overcomes geographical and time barriers. Massive Open Online Courses are a modern form of distance education that creates prerequisites for life-long learning. The purpose of the current work is to investigate the nature, distinctive features and models of Massive Open Online Courses. The main elements of the courses, which are provided to learners through learning platforms, are systematized.
\end{abstract}

Key words: Massive Open Online Courses, distance education, learning platforms

\section{INTRODUCTION}

Distance education has emerged as a solution to the existing need for more opportunities for people to learn and overcoming the constraints of traditional forms of training. In distance education there is a physical separation of learners, who study at their own pace and at a convenient time. To ensure interaction and communication between the main participants in the learning process, a variety of technologies are used. The first stages of distance education are distinguished by the provision of learning materials from teachers to learners with minimal communication between them. The idea of modern distance education is to exploit the potential of information and communication technologies and provide opportunities for learning to all people who have the need and desire to acquire knowledge and skills throughout their lives.

Massive Open Online Courses (MOOCs) are one of the modern forms of distance education. They provide conditions for comprehensive life-long learning, allow members of the society to gain knowledge, competencies and skills when they have an internally recognized necessity or are in need of additional professional qualification.

*Correspondence to: Gabriela Kiryakova, Faculty of Economics, Trakia University - Stara Zagora, Bulgaria, gabriela@uni-sz.bg
There is a controversy over whether Massive Open Online Courses are a form of distance education. Some authors believe that such courses are a kind of self-learning. The refutation of these claims is the fact that many of the massive online courses are offered by well-established educational institutions, and certificates are issued upon successful completion.

The purpose of the current work is to reveal the essence, distinctive features and models of Massive Open Online Courses, which are one of the most popular forms of distance education. The main components of the open courses are systematized.

\section{NATURE AND CHARACTERISTICS OF MASSIVE OPEN ONLINE COURSES}

Massive Open Online Courses are online courses that are conducted and accessible through the Web [1]. They are with open access and an unlimited number of users can subscribe and attend (Figure 1).

Dave Cormier used the term MOOC in 2008 to outline the Connectivism and Connective Knowledge course, created by Canadian professors George Siemens and Stephen Downes. The course was offered for both a small number of students for a fee and over 2000 users online for free [2]. 


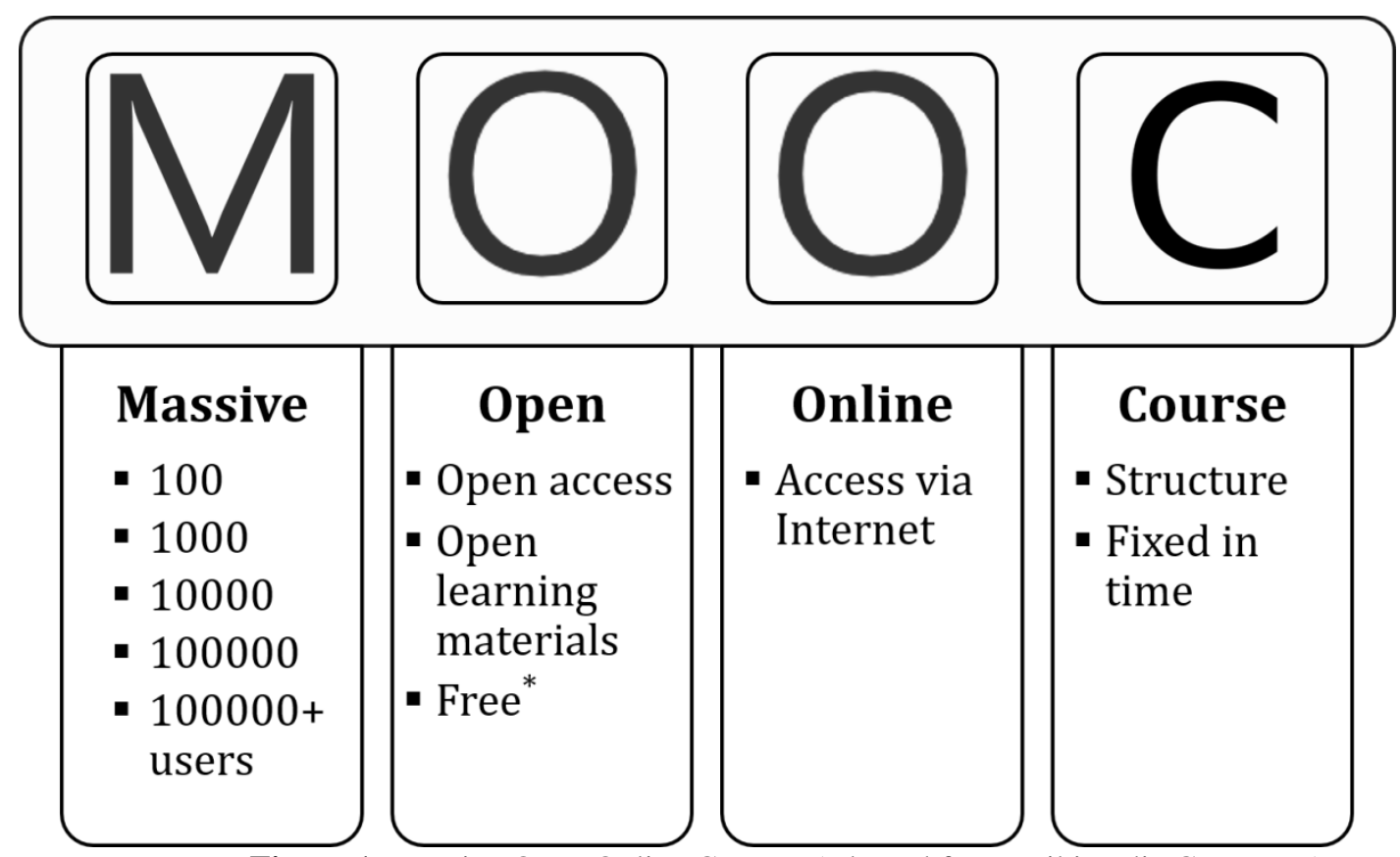

Figure 1. Massive Open Online Courses (adapted from Wikimedia Commons).

MOOCs are based on the concept of free accessible, global, video-based courses that are realized through online platforms. They are used by a large number of learners to gain additional knowledge, skills and competencies. The main distinctive features of MOOCs are openness, structuredness, massiveness, presence of interaction and communication between participants, and underlying on the Connectivism paradigm [3, 4].

- Open. Characteristic Open contains various interpretations. On the one side, the courses and educational resources are provided through systems that can be used by everyone - the registration and participation of users is free. On the other side, the access to the educational resources is free-activities and course content are shared and publicly available. Those massive courses that offer a certificate require the payment of a fee, so open can not be identified with free.

- Massiveness. The courses and the supporting platforms allow access and participation of a large number of users, which significantly exceeds the groups in the traditional training. This is one of the characteristics that distinguishes MOOCs from all other forms of online training and courses.

- Structuredness. Massive courses are restricted in time and have a particular structure. Each course has pre-defined learning objectives to be met by the participants. Users achieve goals by working with learning content and performing certain learning activities. Different forms and tools for evaluating the knowledge acquired by the participants are available.

- Connectivism. MOOCs are based on the Connectivism paradigm. The basic idea of this pedagogical approach is that knowledge is spread across a network of participants. Most of the course activities take place in a shared learning environment where learners work and study together.

- Interaction and communication. To realize the idea of connectivity, it is necessary to have the means by which the learners can interact and communicate with teachers and each other. Among the most popular forms of communication are discussions and forums where users can talk about topics and issues of the curriculum.

These features of massive courses as well as the provision of high-quality content developed by experts from some of the most prestigious universities, explain their widespread distribution and the large number of participants. Learners receive flexible access to training without the need to invest significant financial resources and time, which is very important in contemporary society. They have the opportunity to choose courses among a wide variety of thematic areas, lecturers, experts and educational organizations.

The MOOCs also have some negative aspects, including the lack of direct contact and realtime interaction between participants, which is inherent in distance education. Social 
exclusion can be a cause for a poor performance, lack of motivation, and low efficiency of learning. Several observations and studies of MOOCs [5] mark a large percentage of users who register in courses but do not take part in them and a very small percentage of participants that receive a certificate as a document proving completion of the course. To change these negative trends, different techniques should be applied to provoke learners to be active, motivated, committed and responsible for their own learning.

\section{MOOCS MODELS}

Two MOOCs models can be distinguished cMOOCs and xMOOCs.

cMOOCs (connectivist MOOCs) are considered as the first phase in the development of MOOCs and are often called the original MOOCs. They are structured as open online communities of learners. cMOOCs are based on the educational principles and the philosophy of Connectivism, emphasizing on the power of the social interaction in generating knowledge [6].

The training and learning are implemented in a network of connected tools - different digital collaborative platforms such as blogs, wiki systems, social networks. This is a new type of learning environment where participants are the main drivers of learning, who interact with each other, share knowledge, experience and ideas, and solve problems. Each participant contributes and enriches with his knowledge to the knowledge of others. The standard forms for evaluating learners' knowledge, such as tests and assignments are not available. The teachers' of experts' feedback to course participants can be seen as an informal form of assessment. The links between participants are many to many with multiple conversations in both groups and individuals [7].

xMOOCs (eXtented MOOCs) are the second phase of MOOCs development. Gradually MOOCs are being created and offered by large universities and delivered through their elearning and distance learning platforms or through specially developed systems. xMOOCs are based on the philosophy of cognitivism and behaviorism. They rely on the traditional concept of transferring knowledge from teachers to learners. In the center of the learning process is the teacher [8]. xMOOCs implementation is in the form of traditional online courses with a clearly defined curriculum and a fixed structure.
KIRYAKOVA G. A distinguished feature of $x M O O C s$ is the high-quality learning content created by experts. It is provided to learners in the form of short video lectures. In addition to the main content, learners can also use other materials audio files, presentations, links to Web resources that enable them to expand their knowledge of a particular topic. The courses provide tools, such as online quizzes and assignments for assessing learners' knowledge and skills. The quizzes are automatically evaluated with immediate feedback. The assignments are assessed by the teacher or by other learners to ensure their active participation in training.

Forums and discussions are tools for communication between users. In discussions, learners have the opportunity to share their experience, which can enrich and support the other participants. They can receive guidance, help, clarification, mainly by teachers, but also by the other learners.

Both models (cMOOCs and xMOOCs) have a common goal - to provide opportunities for open training for everyone. The differences lie in the learning environment that is being created. According to [9] cMOOCs focus on creating and generating knowledge, while xMOOCs provide duplication of knowledge. The main criticism of xMOOCs is the lack of strong interaction among learners. However, xMOOCs are more widespread model being provided at this moment.

\section{PLATFORMS FOR PROVIDING MOOCs}

MOOCs are implemented and delivered through learning management platforms. They allow the registration of a large number of participants, the storage of a significant amount of learning materials, and tools for automatic evaluation of quizzes or assignments [7]. Platforms also have tools to track users' progress and analyze data about their performance in order to help teachers in course improvement.

Popular platforms for MOOCs are Coursera, Udacity, Udemy, EdX, FutureLearn, Saylor Academy, OpenLearning, FUN-MOOC, Open2Study, OpenUpEd, Janux, Stanford Online, EMMA, Canvas Network and others. The massive online courses have several common components, regardless of the platforms used for their creation $[10,11]$ :

- Standardized format. Courses are organized on a weekly or thematic basis. The structure and organization depend on the 
purpose of the course - whether users will work at their own pace or there is a planned development.

- Video lectures. The learning content is presented in the form of short video lectures, recorded by lecturers, lasting up to 10 minutes. Another common option is the integration of other media such as YouTube. Video subtitles are available in English and, in some cases, in other languages. Video lectures and subtitles can be downloaded for free by participants.

- Reading materials. Each course offers a text alternative of video lectures and additional materials for reading.

- Integrated activities. In addition to the learning content, courses also include learning activities - questions and quizzes. Usually, each module or week ends with a quiz, assignment or project that should be performed by the participants to determine the extent to which they have mastered the content. The questions are embedded in video lectures or organized into quizes as separate items in each module. Immediate feedback is available since questions are automatically evaluated. In many courses, the projects and assignments are subject to mutual evaluation, which ensures the active participation of learners.

- Discussion forums. An unchanging part of each course is the ability for every learner to communicate with others. Communication is possible in discussion forums where the participants comment and discuss issues related to course topics, solve problems or share opinions.

- Final Exam/Project. In order to determine whether the learning objectives are achieved or in other words, whether the learners have acquired the required knowledge, skills and competences, it is necessary to conduct a final exam. The final step is usually in the form of a quiz or an assignment (project). Some courses provide opportunities for multiple attempts until positive results are achieved.

After the successful completion of some courses, the participants can receive certificates, but they have to pay a fee, even if the course is free of charge. The partnership between MOOCs platforms and different universities allows learners, after positive results in certain courses, to obtain credits that are recognized by the educational institutions. Even is possible to acquire a master's or a bachelor's degree by enrolling in programs offered by universities and delivered through MOOCs platforms.
Alongside with MOOCs, other platforms that provide free remote access to educational resources are developing - Khan Academy, ALISON, Peer-to-Peer-University and others. They are not considered as MOOCs and distinguish from them in two main characteristics - they are not maintained and offered by educational institutions and emphasize on self-learning.

\section{CONCLUSION}

Information and communication technologies are part of everyday life. Our society is transformed into a digital society and its members are constantly in need of new skills, knowledge and competences in different fields. Massive Open Online Courses are a tool for additional and life-long learning. They are based on the concept of open, online, global courses accessible through platforms that are used by a large number of learners. Through them, learners have flexible access to training without the need for significant financial investments. They use high-quality learning content developed by experts from prestigious universities and have the opportunity to collaborate with people all over the world. Massive courses even can complement and enrich the traditional model of formal education. They are one of the most popular form of contemporary distance education.

\section{REFERENCES}

1. Wikipedia, https://www.wikipedia.org/ (last access 08.07.2019).

2. Maxwell, K., Macmillan Dictionary, https://www.macmillandictionary.com/buz zword/entries/mooc.html (last access 08.07.2019).

3. McAuley, A., Stewart, B., Siemens, G., \& Cormier, D., The MOOC model for digital practice, 2010.

4. Baturay, M. H. An overview of the world of MOOCs. Procedia-Social and Behavioral Sciences, 174, 427-433, 2015.

5. Bates, T., The strengths and weaknesses of MOOCs: Part I, https://www.tonybates.ca/2014/10/19/thestrengths-and-weaknesses-of-moocs-part-i/ (last access 08.07.2019).

6. Ospina-Delgado, J., Zorio-Grima, A., \& García-Benau, M. Massive open online courses in higher education: A data analysis of the MOOC supply. Intangible Capital, 12(5), 1401-1450, 2016.

7. Bates B., Comparing xMOOCs and cMOOCs: philosophy and practice, https://www.tonybates.ca/2014/10/13/com 
KIRYAKOVA G.

paring-xmoocs-and-cmoocs-philosophyand-practice/ (last access 08.07.2019).

8. Rodriguez, O.: The concept of openness behind $\mathrm{c}$ and $\mathrm{x}$-moocs (massive open online courses). Open Praxis 5 (1), 2013

9. What is the Difference Between xMOOCs and cMOOCs?, Online Education Blog of TouroCollege,http://blogs.onlineeducation. touro.edu/distinguishing-between-cmoocsand-xmoocs/ (last access 08.07.2019)

10. Grainger, B. Massive open online course (MOOC) report 2013.

11. The Best MOOC Platforms, Reviews.com, https://www.reviews.com/moocplatforms/, (last access 08.07.2019) 